Article

\title{
Effects of Different Light Sources on Neural Activity of the Paraventricular Nucleus in the Hypothalamus
}

\author{
Michio Yokoyama ${ }^{1}$, Hyukki Chang ${ }^{2}$, Hiroshi Anzai ${ }^{3}$ and Morimasa Kato ${ }^{4, *}$ \\ 1 Graduate School of Science and Engineering, Yamagata University, Yonezawa 992-8510, Japan; \\ yoko@yz.yamagata-u.ac.jp \\ 2 Department of Human Movement Science, Seoul Women's University, Seoul 01797, Korea; \\ hkchang@swu.ac.kr \\ 3 Takahata Electronics Corporation, Yonezawa 992-0003, Japan; h-anzai@takahata-denshi.co.jp \\ 4 Department of Health and Nutrition, Yamagata Prefectural Yonezawa University of Nutrition Sciences, \\ Yonezawa 992-0025, Japan \\ * Correspondence: m-kato@yone.ac.jp; Tel.: +81-238-22-7375
}

Received: 30 September 2019; Accepted: 6 November 2019; Published: 9 November 2019

check for updates

\begin{abstract}
Background and Objectives: Physical function is influenced by light irradiation, and interest in the influence of light irradiation on health is high. Light signals are transmitted from the retina to the suprachiasmatic nucleus (SCN) via the retinal hypothalamic tract as non-image vision. Additionally, the SCN projects a nerve to the paraventricular nucleus (PVN) which acts as a stress center. This study examined the influences of three different light sources on neural activity in the PVN region using two different color temperatures. Materials and Methods: Experiments were conducted using twenty-eight Institute of Cancer Research (ICR) mice (10 week old males). Three light sources were used: (1) organic light-emitting diode (OLED) lighting, (2) LED lighting, and (3) fluorescent lighting. We examined the effects of light irradiation from the three light sources using two different color temperatures $(2800 \mathrm{~K}$ and $4000 \mathrm{~K}$ ). Perfusion was done $60 \mathrm{~min}$ after light irradiation, and then the brain was removed from the mouse for an immunohistochemistry analysis. c-Fos was immunohistochemically visualized as a marker of neural activity in the PVN region. Results: The number of c-Fos-positive cells was found to be significantly lower under OLED lighting and LED lighting conditions than under fluorescent lighting at a color temperature of $2800 \mathrm{~K}$, and significantly lower under OLED lighting than LED lighting conditions at a color temperature of $4000 \mathrm{~K}$. Conclusions: This study reveals that different light sources and color temperatures alter the neural activity of the PVN region. These results suggest that differences in the light source or color temperature may affect the stress response.
\end{abstract}

Keywords: organic light-emitting diode lighting; LED lighting; fluorescent lighting; color temperature; immunohistochemistry analysis; stress response

\section{Introduction}

Physical functions are regulated by lighting factors such as intensity, components of radiated light, and exposure duration. These light irradiations alter autonomic activity and the endocrine response, which control body temperature, the sleep-wake cycle, and also induce psychological changes [1-4].

Recently, more attention has been paid to the association between exposure to components of radiated light and health problems. In particular, the discovery of the photoreceptive intrinsically reactive retinal ganglion cells (ipRGCs) [5,6] has led to an increasing need for research on light irradiation and brain function. These cells are most sensitive to blue light [5], and neural projections from ipRGCs to the suprachiasmatic nucleus (SCN) through the retinohypothalamic tract have been observed [7-11]. Changes in the circadian rhythm and the inhibition of melatonin secretion caused by 
blue light are implicated in this pathway, because the SCN is a central circadian pacemaker [12-14]. The influence of blue light on health has been reported to improve cognitive function and reaction time [15-17]. Furthermore, blue light therapy has also been reported to be effective for the treatment of mild traumatic brain injury [18] and depression [19]. As described above, light irradiation may affect several regions in the brain. Indeed, neuronal projections in the brain are also projected from the SCN to the hypothalamic paraventricular nucleus (PVN), which is the center of stress regulation [20,21]. For this reason, light irradiation may also be related to stress responses.

In addition, color temperature (Kelvin), which is the scale used to measure emissions from a light source, is also an important factor in understanding the influence of light on physiological and psychological responses [22,23]. The color becomes blue when the temperature is higher and orange when the temperature is lower. Deguchi et al. [23] reported a contingent negative variation (CNV) response from electroencephalogram (EEG) of 11 human participants and found that a higher color temperature activated the reticular activating system more than a lower color temperature. Results from mice studies associated a higher color temperature with an increased stress and anxiogenic response [24]. These studies indicate that further research on light irradiation and brain function is needed to examine color temperature in more depth.

Considering our daily lives, the effects of light components and color temperature on brain function are mainly affected by differences in light sources such as fluorescent light, LED, and organic light-emitting diode (OLED). There is limited knowledge of the effects of different light sources on brain function. In a sleep study, Rahman et al. [25] compared fluorescent lighting with LED lighting when the blue light region was cut. They found that the power value of the delta-wave in the EEG signals was significantly elevated by blue-depleted LED lights compared with fluorescent lights. Additionally, Yuda et al. [26] found that relative to fluorescent lighting, OLED lighting was associated with lower heart rates and a greater high-frequency power component, which is an indicator of parasympathetic nerve activity. It was suggested that the changes in the psychological response and brain function were caused by the differences in the light source.

A non-image forming signal from the retina, which is received by the neural network and photoreceptors, is transmitted through the retinohypothalamic tract to the SCN [7-11], and neurons also project from the SCN to the PVN, which is the center of the stress regulation region. This study examined the effect of light irradiation produced by three different light sources on the neural activity of the hypothalamic/PVN area. We hypothesized that the difference in light source may alter the neural activity of the PVN.

\section{Methods}

\subsection{Experimental Animals}

Ten week old male Institute of Cancer Research (ICR) mice $(n=28)$ weighing between 32.3 and $47.1 \mathrm{~g}$ were obtained from CLEA, Japan, Inc. (Tokyo, Japan). All mice were housed singly in cages $(125 \mathrm{~mm} \times 113 \mathrm{~mm} \times 197 \mathrm{~mm})$ and maintained on a $12 \mathrm{~h}$ day/night cycle (light from 08:00 to 20:00 (a fluorescent lamp; $388 \pm 13 \mathrm{~lx}$ ) and darkness from 20:00 to 08:00) in an air-conditioned room with a temperature and humidity of $23 \pm 2$ degrees Celsius and 50\% $\pm 10 \%$, respectively. During the rearing period, the animals received commercial rodent chow (CE2, CLEA Japan Inc., Tokyo, Japan) and water ad libitum. For habituation to the laboratory conditions, the animals were housed for 2 weeks, and then the study was started. All procedures were performed in accordance with the Institutional Guidelines for Animal Care at the National Institute of Health Guidelines for the Care and Use of Laboratory Animals. The proposal for the use of animals was received and approved by the animal care review committee of the Yamagata Prefectural Yonezawa University of Nutrition Sciences (Approval Number 226, date of approval 30 October 2015). 


\subsection{Experimental Design}

This study was conducted under light irradiation conditions using three different light sources and two different color temperatures. The following three light sources were used: (1) OLED lighting, (2) LED lighting, and (3) fluorescent lighting, and we examined the effects of light irradiation from the three light sources using two different color temperatures ( 2800 and $4000 \mathrm{~K}$ ). The illumination intensity was set at $500 \pm 10 \mathrm{~lx}$ for all light sources. Light irradiation was conducted under each condition for $1.5 \mathrm{~h}$ using each light source one hour before the start of the light period in order to minimize the effect on the circadian rhythm by eliminating the effect of the light history. During light irradiation, the light source was placed outside of the breeding equipment. A blackout curtain with an opening area of $75 \mathrm{~mm} \times 260 \mathrm{~mm}$ was placed on the breeding equipment to maintain a constant level of light irradiation. When evaluating the spectral composition of the lighting source, the measurement position of the illuminance spectrophotometer and the cage position of the mouse during light irradiation were at the same distance. The mouse cage was transparent, and nothing in the breeding equipment absorbed light. Therefore, the light received by the mouse was similar to the state measured by the spectrophotometer (Figure 1).

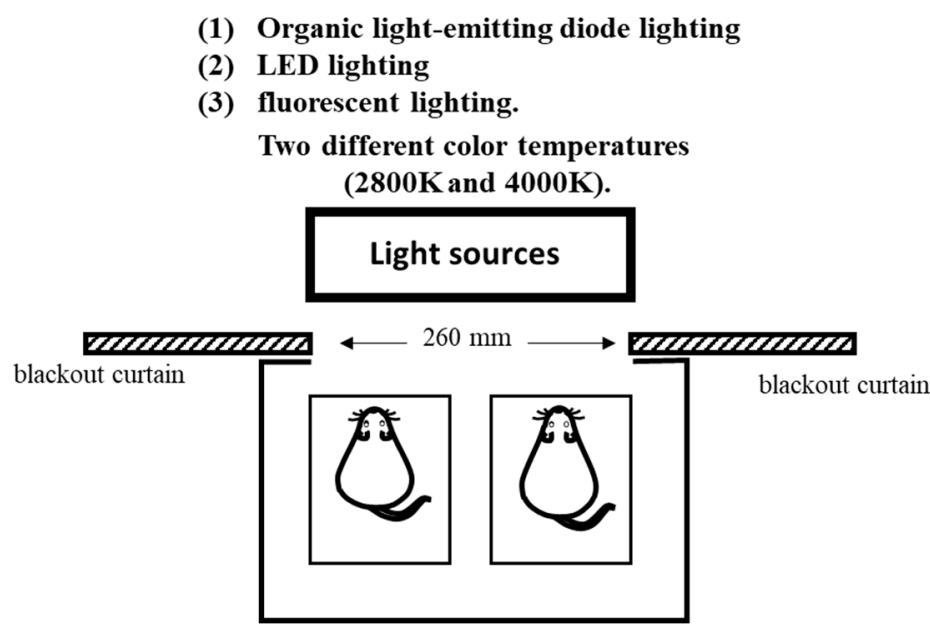

Figure 1. Light irradiation on mouse cage.

\subsection{Immunohistochemistry}

Mice were anesthetized with isoflurane, perfused with $200 \mathrm{~mL}$ of $0.9 \%$ saline (at $60 \mathrm{~min}$ after the light emission), and then perfused with $300 \mathrm{~mL}$ of $4 \%$ paraformaldehyde in $0.1 \mathrm{M}$ of phosphate buffered salts (PBS, pH 7.4). Then, the brains from the mice were quickly removed for immunohistochemistry analysis. The brain samples were placed in $20 \%$ sucrose, frozen on dry ice, and finally stored at $-80^{\circ} \mathrm{C}$ until sectioning. Frozen serial frontal sections ( $40 \mu \mathrm{m}$ thick) were taken from the PVN. The brain sections were made using a cryo-microtome (CM1900; Leica Microsystems, Nussloch, Germany). An immunohistochemical visualization of c-Fos was carried out on free-floating sections using antibody and avidin-biotin-peroxidase methods. The free-floating sections were incubated with $0.3 \% \mathrm{H}_{2} \mathrm{O}_{2}$, permeabilized with $0.3 \%$ Triton X-100, and nonspecific protein binding was blocked by incubation with $3 \%$ normal goat serum. The sections were incubated overnight at $4{ }^{\circ} \mathrm{C}$ with anti-c-Fos antibody $(1: 2000$, rabbit polyclonal; Oncogene Research Products, San Diego, CA, USA). The sections were rinsed three times (10 min each) in phosphate-buffered saline with triton (PBT) and incubated with biotinylated goat anti-rabbit IgG (1:200; Vectastain Elite avidin-biotin complex (ABC) kit, Vector Laboratories, Burlingame, CA, USA) for $1 \mathrm{~h}$. The sections were rinsed three times (10 min each) in PBT, incubated with $A B C$ solution (1:50; Vectastain Elite $A B C$ kit) for $1 \mathrm{~h}$, and visualized using the diaminobenzidine (DAB) procedure method. The reaction was stopped by transferring the sections into $0.1 \mathrm{M}$ acetate 
buffer and rinsing twice (5 min each) in PBT. After drying, the sections were mounted on glass slides using Eukitt (Kindler, Freiburg, Germany).

\subsection{Data Analysis}

\subsubsection{Light Source Analysis}

The spectral compositions of the lighting sources were obtained for every lighting condition using an Illuminance Spectrophotometer (Konica Minolta CL-500A, Tokyo, Japan). The spectral power distribution, color temperature (Kelvin), and illuminance (lx) data were recorded at each cage position. The position of the illuminance spectrophotometer position was at the same distance as the cage position when the mouse was irradiated with light. In addition, quantification of the four photoreceptors' (melanopsin, rods, and $\mathrm{m}$ - and s-cone) inputs in mice was conducted using the toolbox reported by Lucus' group $[27,28]$.

\subsubsection{Analysis of the c-Fos-Positive Cell Number}

The tissue sections were scanned using an All-in-One Fluorescence Microscope (BZ-X700, Keyence, Osaka, Japan). The images obtained from the PVN in a mouse brain atlas were overlaid using paint.net, which is an image and photo editing software. Then, we manually counted the number of c-Fos positive cells in the PVN.

\subsection{Statistics}

We calculated the mean and standard deviation (SD) of the number of brain cells by light source and by color temperature. Then, we analyzed the primary effects of the light source and color temperature and their interactions by two-way ANOVA using the number of brain cells as the dependent variable and the light source, color temperature, and the interaction between light source and color temperature as independent variables. Subsequently, we performed a multiple comparisons test using Tukey's honestly significant difference (HSD) method to compare the light sources based on the results of the variance analysis, and we performed an unpaired t-test to compare the color temperatures. A statistical analysis was performed using the SPSS statistics package software, version 22. (IBM Japan, Tokyo, Japan). A risk rate of less than $5 \%$ was regarded as representing a significant difference.

\section{Results}

\subsection{Light Irradiation}

Figure 2 shows the spectral composition of each light source. The peak wavelength of each light source was as follows: The peak wavelength of the OLED light was $601.7 \mathrm{~nm}$ at $2800 \mathrm{~K}(602$, 601 , and $602 \mathrm{~nm}$ for the three measurements) and $613.5 \mathrm{~nm}$ at $4000 \mathrm{~K}$ ( 613 and $614 \mathrm{~nm}$ for the two measurements). The peak wavelength of the LED light was $609 \mathrm{~nm}$ at $2800 \mathrm{~K}$ (609 and $609 \mathrm{~nm}$ for the two measurements) and $450 \mathrm{~nm}$ at $4000 \mathrm{~K}$ (450 and $450 \mathrm{~nm}$ for the two measurements). The peak wavelength of the fluorescent light was $612 \mathrm{~nm}$ at $2800 \mathrm{~K}$ ( 612 and $612 \mathrm{~nm}$ for the two measurements) and $544 \mathrm{~nm}$ at $4000 \mathrm{~K}$ (544 and $544 \mathrm{~nm}$ for the two measurements). 
A $2800 K$
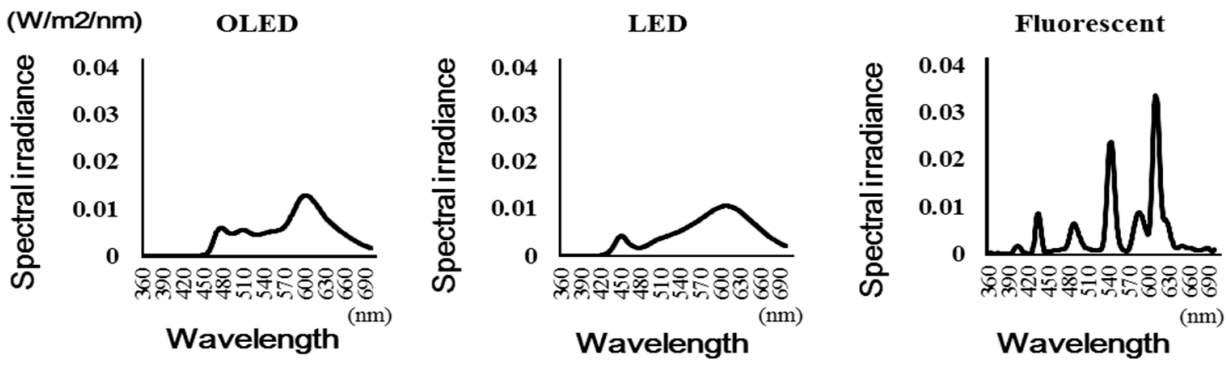

\section{B $4000 K$}
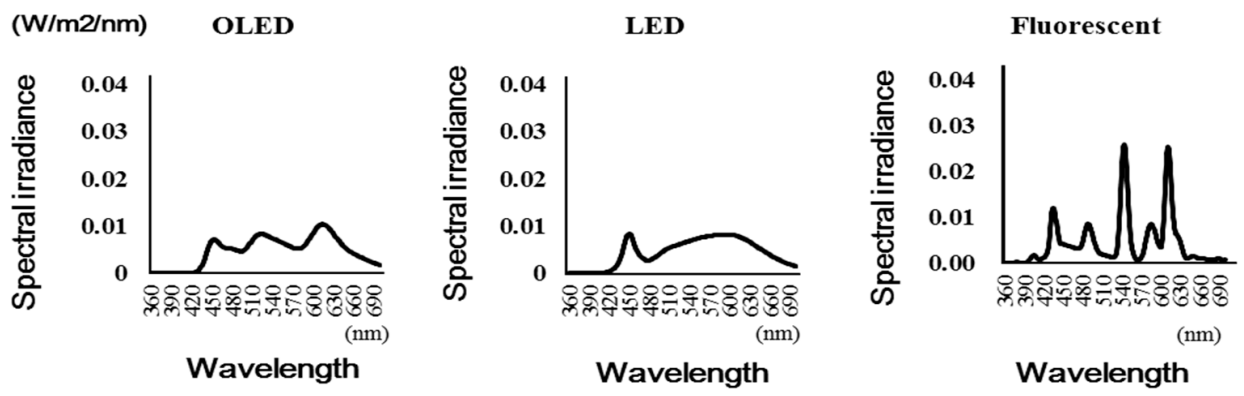

Figure 2. Spectral composition of each light source. (A): 2800 Kelvin (B): 4000 Kelvin.

Figure 3 shows the spectral distribution of the $\alpha$-opic lux values of each photoreceptor (melanopsin, rods, and $\mathrm{m}$ - and s-cones). Table 1 shows the maximum value of the $\alpha$-opic lux of each photoreceptor and the frequency. The LED had a peak at around $450 \mathrm{~nm}$ when evaluated with the melanopsin receptor. Under fluorescent light, the S-cone showed a value more than 10 times that of the other light sources.

\section{A $\mathbf{2 8 0 0 K}$}

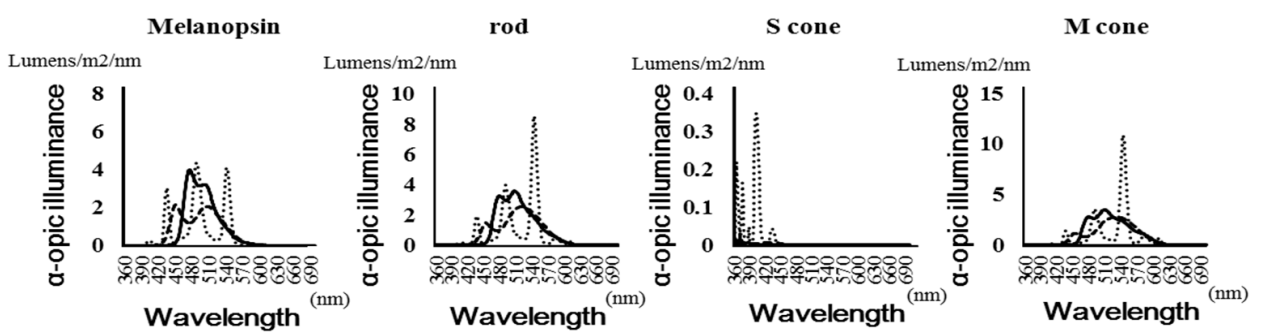

B $4000 K$
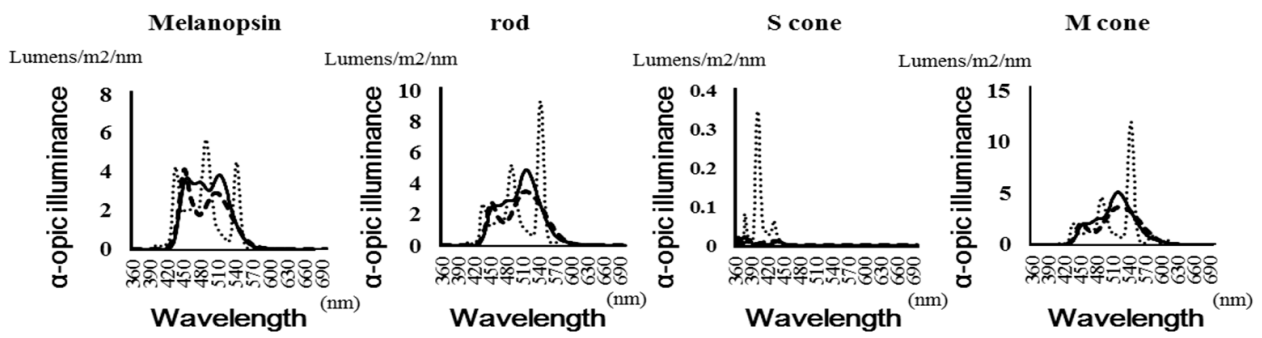

Figure 3. Spectral distribution of the $\alpha$-opic lux values of each photoreceptor. (A): 2800 Kelvin (B): 4000 Kelvin.

The solid line is OLED, the thick dotted line is LED light, and the fine-dotted line is fluorescent light. 
Table 1. Maximum value of the $\alpha$-opic lux and frequency of each photoreceptor.

\begin{tabular}{|c|c|c|c|c|c|c|c|c|c|}
\hline \multirow{3}{*}{$\begin{array}{c}\text { Color } \\
\text { Temperature }\end{array}$} & \multirow{3}{*}{ Light Source } & \multicolumn{2}{|c|}{ Melanopsin } & \multicolumn{2}{|c|}{ Rods } & \multicolumn{2}{|c|}{ S cone } & \multicolumn{2}{|c|}{ M cone } \\
\hline & & $\begin{array}{l}\alpha \text {-Opic Lux } \\
\text { Value }\end{array}$ & $\begin{array}{c}\text { Peak } \\
\text { Wavelength }\end{array}$ & $\begin{array}{l}\alpha \text {-Opic Lux } \\
\text { Value }\end{array}$ & $\begin{array}{c}\text { Peak } \\
\text { Wavelength }\end{array}$ & $\begin{array}{l}\alpha \text {-Opic Lux } \\
\text { Value }\end{array}$ & $\begin{array}{c}\text { Peak } \\
\text { Wavelength }\end{array}$ & $\begin{array}{l}\alpha \text {-Opic Lux } \\
\text { Value }\end{array}$ & $\begin{array}{c}\text { Peak } \\
\text { Wavelength }\end{array}$ \\
\hline & & (Lumens $/ \mathrm{m}^{2} / \mathrm{nm}$ ) & $(\mathrm{nm})$ & (Lumens $/ \mathrm{m}^{2} / \mathrm{nm}$ ) & $(\mathrm{nm})$ & (Lumens $\left./ \mathrm{m}^{2} / \mathrm{nm}\right)$ & $(\mathrm{nm})$ & (Lumens/m²/nm) & $(\mathrm{nm})$ \\
\hline \multirow{3}{*}{$2800 \mathrm{~K}$} & OLED & 3.973 & 477 & 3.552 & 507 & 0.023 & 360 & 3.47 & 509 \\
\hline & LED & 2.143 & 452 & 2.513 & 519 & 0.029 & 372 & 2.75 & 531 \\
\hline & Fluorescent & 4.362 & 489 & 8.506 & 543 & 0.347 & 402 & 10.888 & 544 \\
\hline \multirow{3}{*}{$4000 \mathrm{~K}$} & OLED & 3.854 & 512 & 4.887 & 517 & 0.015 & 387 & 5.11 & 520 \\
\hline & LED & 4.11 & 452 & 3.477 & 516 & 0.03 & 368 & 3.672 & 525 \\
\hline & Fluorescent & 5.719 & 489 & 9.345 & 543 & 0.348 & 402 & 11.913 & 543 \\
\hline
\end{tabular}

(O)LED: (organic) light emitting diode. 


\section{2. c-Fos-Positive Cell Number}

Figure 4 shows the c-Fos-positive cell number for each light source, as follows: For OLED light, $8.4 \pm 4.3$ at $2800 \mathrm{~K}$ and $20.0 \pm 11.8$ at $4000 \mathrm{~K}$; for LED light, $16.6 \pm 5.9$ at $2800 \mathrm{~K}$ and $47.1 \pm 20.8$ at $4000 \mathrm{~K}$; and for fluorescent light, $27.4 \pm 8.4$ at $2800 \mathrm{~K}$ and $31.3 \pm 16.9$ at $4000 \mathrm{~K}$.

\section{A}

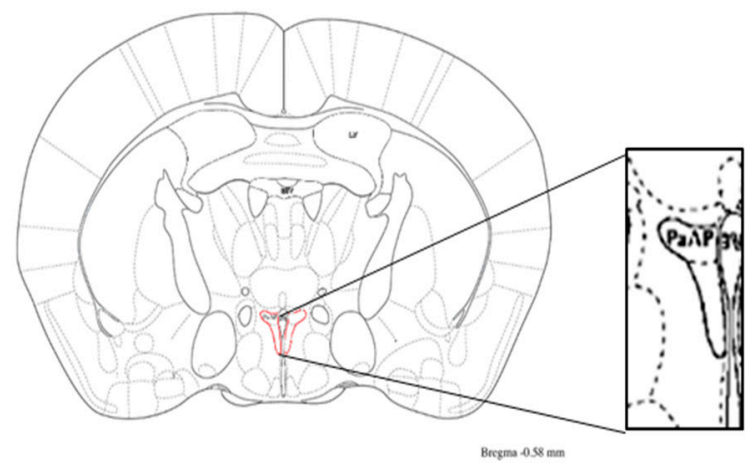

B
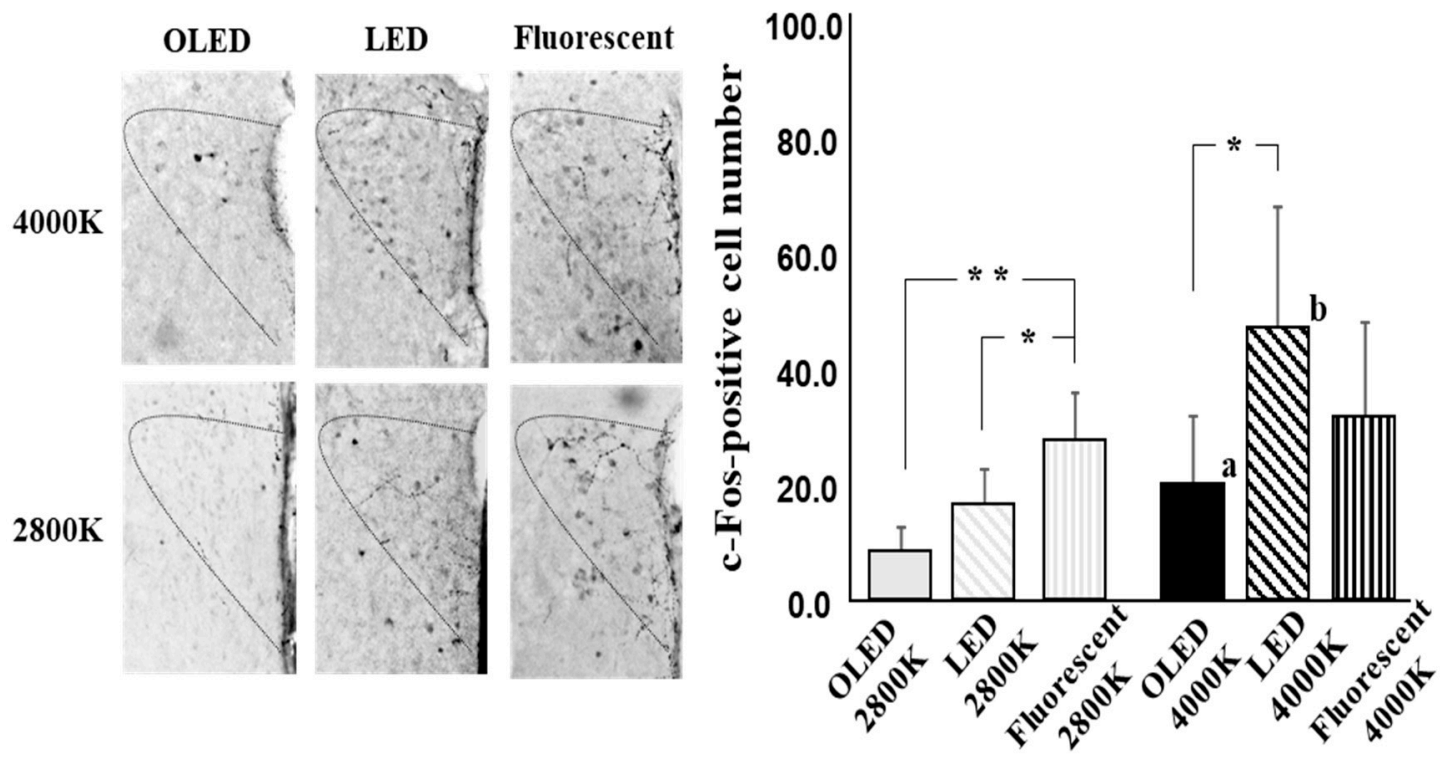

a: significant difference from $2800 \mathrm{~K}(\mathrm{p}<0.05)$

b: significant difference from $2800 \mathrm{~K}(\mathrm{p}<0.01)$

* : significant difference $(p<0.05)$

$* *$ : significant difference $(p<0.01)$

Figure 4. Comparison of each light source, comparison of color temperature. (A) Analysis of brain region (B) c-Fos-positive cells number for each light source at two color temperature. All data on the figure expressed as mean \pm SD. a: significant difference from $2800 \mathrm{~K}(p<0.05)$, b: significant difference from $2800 \mathrm{~K}(p<0.01),{ }^{*}$ : significant difference $(p<0.05),{ }^{* *}$ : significant difference $(p<0.01)$.

The two-way ANOVA gave the following results: light source: $\mathrm{F}((2.36)=5.8, p=0.006)$, color temperature: $\mathrm{F}((1,36)=12.5, p=0.001)$, and light source $\times$ color temperature: $\mathrm{F}((2,36)=3.7, p=0.034))$.

The comparison of the light sources revealed a significant difference between OLED lighting and fluorescent lighting and between LED lighting and fluorescent lighting for the $2800 \mathrm{~K}$ lamp and between OLED lighting and LED lighting for the $4000 \mathrm{~K}$ lamp. The comparison of color temperature 
showed a significant difference between OLED lighting and LED lighting, with the $4000 \mathrm{~K}$ lamp showing significantly higher positive numbers than the $2800 \mathrm{~K}$ lamp.

\section{Discussion}

Using two different color temperatures, this study revealed, for the first time, that a difference in light source can alter neural activity in the stress-related region of the hypothalamic area. It was found that the c-Fos expression within PVN at each color temperature was lowest under OLED light conditions compared with the other tested light source conditions. Furthermore, an increase in color temperature led to a significant increase in c-Fos expression within PVN in OLED and LED conditions. The above results suggest that differences in the light source or color temperature may affect the stress response.

In this study, we confirmed that c-Fos expression was lower in the PVN under OLED light compared with other light sources when the color temperature was the same for each light source. It is speculated that this factor may have be caused by the effect of blue light on the ipRGCs and s-cone photoreceptors. Since it is considered that light from an external source is received by photoreceptors, it becomes a neural signal which is transmitted through the retinohypothalamic tract to the SCN [7-11]. Furthermore, this signal is transmitted from the SCN to the PVN, which controls the physiological functions through endocrine and autonomic responses [19,20,29]. A previous study reported a more efficient response of the ipRGCs to blue light compared to other photoreceptors, and it is believed that the wavelength region of $440-450 \mathrm{~nm}$ has the highest level of blue light energy [30]. Mei-Ling Peng et al. [31] examined the impacts of domestic LED lamps on the retinas of mice and found that peak retinal degeneration occurred at $450 \mathrm{~nm}$ within the wavelength range of blue light. Moreover, this study indicated that the melanopsin-integrated $\alpha$-opic lux value of $440-450 \mathrm{~nm}$ was highest under the LED condition and lowest under OLED. Therefore, it is speculated that the difference in irradiance in this wavelength range may affect c-Fos expression in the PVN, and this difference may explain the low expression level of c-Fos under the OLED condition.

In addition, it is suggested that the color temperature may affect the expression of c-Fos in the PVN. Previous human studies reported enhancement of sympathetic nerve activity and the arousal level and suppression of melatonin secretion by increasing the color temperature [32]. Animal studies also reported an association between higher frequencies of stress behaviors and an increase in color temperature [24]. This study linked an increase in color temperature to higher c-Fos expression for each light source. Particularly in LED and OLED conditions, a significant increase in c-Fos expression was found due to an increase in color temperature. However, in this study, we only found a small increase in c-Fos expression under fluorescent conditions following the increase in the color temperature. This factor may be responsible for the effect in the UV region from the fluorescent lamp light source. In addition, the results of this study indicate that wavelengths lower than $400 \mathrm{~nm}$ are associated with high spectral irradiance under fluorescent conditions compared with other light conditions. Previous reports have indicated that mice have ultraviolet cone receptors and are highly sensitive to short-wavelength light [33]. In fact, the s-cone $\alpha$-opic lux value in this study showed a more than 10 -fold increase under fluorescent lamp conditions compared with the other conditions. Only a small increase in c-Fos expression was reported following the increase in color temperature, because c-Fos expression increased even at a low color temperature under fluorescent conditions compared with the other light conditions.

Stress-related cardiovascular responses, endocrine responses, and autonomic responses are controlled by the PVN, the target of this study [34-36]. Previous studies in humans have reported that different light sources or color temperatures may alter the autonomic activity, psychological state, and working performance [22-26]. For example, it has been indicated that sympathetic nerve activity is increased at high color temperatures in association with autonomic activities [22]. In addition, it has been reported that parasympathetic nerve activity is enhanced to a greater extent under OLED light than under fluorescent light [26]. In this study, marked differences in c-Fos expression were 
observed in the PVN with different light sources. This suggests that the light source may affect the stress response, and this may be lower under OLED light.

This study has several limitations. First, it was not intended to evaluate the damage on the retina caused by light stimuli but rather, was intended to evaluate neural activity in the PVN, which plays a key role in the stress response. Therefore, the irradiation time was short in this study, compared with studies where damage was caused to the retina [37-41]. This may have occurred in response to weak light stimuli in mice. Further studies need to be carried out to assess whether there is a difference between light sources on the level of light stimulation, which can cause damage to the retina. Secondly, we did not measure physiological and/or behavioral data for light stimuli. Subsequent studies need to be carried out to assess the physiological response to light in order to examine the detailed association between the difference in the stress reaction following exposure to various light sources. Furthermore, in order to examine the physiological mechanism, it is also necessary to consider factors including those related to each photoreceptor. In this study, we observed changes in neural activity in the PVN that were associated with different light sources. However, it is unknown which neural cells are involved in the release of hormones from in the PVN, including vasopressin, corticotropin-releasing hormone $(\mathrm{CRH})$, and oxytocin. Thus, there are some limitations in this study. Future research studies should address these limitations.

\section{Conclusions}

In this study, the experiment was examined the influences of three different light sources on neural activity in the PVN region using two different color temperatures. This study carried out with the same illumination intensity under all light source conditions. Therefore, the differences in c-Fos expression in the PVN are presumed to have been due to the difference in the spectral composition of the light sources. Light irradiation from each light source had a characteristic effect on each photoreceptor. The effect on the s-cone was strong with fluorescent lamp irradiation and the effect on melanopsin was strong under the LED condition and weak under the OLED condition at 440-450 nm, which is the blue wavelength energy region. The hypothalamic PVN region is involved in stress regulation, and the results of this study suggest that differences in light source and color temperature affect the stress response.

Author Contributions: Conceptualization, M.Y., H.A. and M.K.; Data curation, H.C., H.A. and M.K.; Formal analysis, M.Y., H.C., H.A. and M.K.; Funding acquisition, M.Y. and H.A.; Investigation, M.K.; Methodology, H.C., H.A. and M.K.; Project administration, M.Y. and M.K.; Supervision, M.K.; Validation, M.Y., H.C. and M.K.; Visualization, M.Y., H.C. and M.K.; Writing—original draft, M.Y., H.C. and M.K.; Writing—review \& editing, M.Y., H.C. and M.K.

Funding: This research received no external funding.

Acknowledgments: This work was supported by Yamagata Promotional Organization for Industrial Technology Grant-in Aid for Yamagata regional industries support fund.

Conflicts of Interest: The authors declare that they have no conflict of interest.

\section{References}

1. Chellappa, S.L.; Lasauskaite, R.; Cajochen, C. In a Heartbeat: Light and Cardiovascular Physiology. Front. Neurol. 2017, 8, 541. [CrossRef] [PubMed]

2. Fisk, A.S.; Tam, S.K.E.; Brown, L.A.; Vyazovskiy, V.V.; Bannerman, D.M.; Peirson, S.N. Light and Cognition: Roles for Circadian Rhythms, Sleep, and Arousal. Front. Neurol. 2018, 9, 56. [CrossRef] [PubMed]

3. Jung, C.M.; Khalsa, S.B.; Scheer, F.A.; Cajochen, C.; Lockley, S.W.; Czeisler, C.A.; Wright, K.P., Jr. Acute effects of bright light exposure on cortisol levels. J. Biol. Rhythms 2010, 25, 208-216. [CrossRef] [PubMed]

4. Lockley, S.W.; Brainard, G.C.; Czeisler, C.A. High sensitivity of the human circadian melatonin rhythm to resetting by short wavelength light. J. Clin. Endocrinol. Metab. 2003, 88, 4502-4505. [CrossRef]

5. Berson, D.M.; Dunn, F.A.; Takao, M. Phototransduction by retinal ganglion cells that set the circadian clock. Science 2002, 295, 1070-1073. [CrossRef] 
6. Hattar, S.; Liao, W.; Takao, M.; Berson, D.M.; Yau, K.W. Melanopsin-containing retinal ganglion cells: Architecture, projections, and intrinsic photosensitivity. Science 2002, 295, 1065-1070. [CrossRef]

7. Fan, S.M.Y.; Chang, Y.T.; Chen, C.L.; Wang, W.H.; Pan, M.K.; Chen, W.P.; Lin, S.J. External light activates hair follicle stem cells through eyes via an ipRGC SCN sympathetic neural pathway. Proc. Natl. Acad. Sci. USA 2018, 115, E6880-E6889. [CrossRef]

8. Hattar, S.; Kumar, M.; Park, A.; Tong, P.; Tung, J.; Yau, K.W.; Berson, D.M. Central projections of melanopsin-expressing retinal ganglion cells in the mouse. J. Comp. Neurol. 2006, 497, 326-349. [CrossRef]

9. Hull, J.T.; Czeisler, C.A.; Lockley, S.W. Suppression of Melatonin Secretion in Totally Visually Blind People by Ocular Exposure to White Light: Clinical Characteristics. Ophthalmology 2018, 125, 1160-1171. [CrossRef]

10. Moldavan, M.G.; Allen, C.N. Retinohypothalamic tract synapses in the rat suprachiasmatic nucleus demonstrate short-term synaptic plasticity. J. Neurophysiol. 2010, 103, 2390-2399. [CrossRef]

11. Ohi, K.; Takashima, M.; Nishikawa, T.; Takahashi, K. N-methyl-D-aspartate receptor participates in neuronal transmission of photic information through the retinohypothalamic tract. Neuroendocrinology 1991, 53, 344-348. [CrossRef] [PubMed]

12. Gabel, V.; Reichert, C.F.; Maire, M.; Schmidt, C.; Schlangen, L.J.M.; Kolodyazhniy, V.; Garbazza, C.; Cajochen, C.; Viola, A.U. Differential impact in young and older individuals of blue-enriched white light on circadian physiology and alertness during sustained wakefulness. Sci. Rep. 2017, 7, 7620. [CrossRef] [PubMed]

13. Hanifin, J.P.; Lockley, S.W.; Cecil, K.; West, K.; Jablonski, M.; Warfield, B.; James, M.; Ayers, M.; Byrne, B.; Gerner, E.; et al. Randomized trial of polychromatic blue-enriched light for circadian phase shifting, melatonin suppression, and alerting responses. Physiol. Behav. 2019, 198, 57-66. [CrossRef] [PubMed]

14. West, K.E.; Jablonski, M.R.; Warfield, B.; Cecil, K.S.; James, M.; Ayers, M.A.; Maida, J.; Bowen, C.; Sliney, D.H.; Rollag, M.D.; et al. Blue light from light-emitting diodes elicits a dose-dependent suppression of melatonin in humans. J. Appl. Physiol. 2011, 110, 619-626. [CrossRef]

15. Alkozei, A.; Smith, R.; Pisner, D.A.; Vanuk, J.R.; Berryhill, S.M.; Fridman, A.; Shane, B.R.; Knight, S.A.; Killgore, W.D. Exposure to Blue Light Increases Subsequent Functional Activation of the Prefrontal Cortex during Performance of a Working Memory Task. Sleep 2016, 39, 1671-1680. [CrossRef] [PubMed]

16. Alkozei, A.; Smith, R.; Dailey, N.S.; Bajaj, S.; Killgore, W.D.S. Acute exposure to blue wavelength light during memory consolidation improves verbal memory performance. PLoS ONE 2007, 12, e0184884. [CrossRef]

17. Knaier, R.; Schäfer, J.; Rossmeissl, A.; Klenk, C.; Hanssen, H.; Höchsmann, C.; Cajochen, C.; Schmidt-Trucksäss, A. Effects of bright and blue light on acoustic reaction time and maximum handgrip strength in male athletes: A randomized controlled trial. Eur. J. Appl. Physiol. 2017, 117, 1689-1696. [CrossRef]

18. Bajaj, S.; Vanuk, J.R.; Smith, R.; Dailey, N.S.; Killgore, W.D.S. Blue-Light Therapy Following Mild Traumatic Brain Injury: Effects on White Matter Water Diffusion in the Brain. Front. Neurol. 2017, 8, 616. [CrossRef]

19. Strong, R.E.; Marchant, B.K.; Reimherr, F.W.; Williams, E.; Soni, P.; Mestas, R. Narrow-band blue-light treatment of seasonal affective disorder in adults and the influence of additional nonseasonal symptoms. Depress Anxiety 2009, 26, 273-278. [CrossRef]

20. Saeb-Parsy, K.; Lombardelli, S.; Khan, F.Z.; McDowall, K.; Au-Yong, I.T.; Dyball, R.E. Neural connections of hypothalamic neuroendocrine nuclei in the rat. J. Neuroendocrinol. 2000, 12, 635-648. [CrossRef]

21. Vrang, N.; Larsen, P.J.; Mikkelsen, J.D. Direct projection from the suprachiasmatic nucleus to hypophysiotrophic corticotropin-releasing factor immunoreactive cells in the paraventricular nucleus of the hypothalamus demonstrated by means of Phaseolus vulgaris-leucoagglutinin tract tracing. Brain Res. 1995, 684, 61-69. [CrossRef]

22. Askaripoor, T.; Motamedzadeh, M.; Golmohammadi, R.; Farhadian, M.; Babamiri, M.; Samavati, M. Non-Image Forming Effects of Light on Brainwaves, Autonomic Nervous Activity, Fatigue, and Performance. J. Circadian Rhythms 2018, 16, 9. [CrossRef] [PubMed]

23. Deguchi, T.; Sato, M. The effect of color temperature of lighting sources on mental activity level. Ann. Physiol. Anthropol. 1992, 11, 37-43. [CrossRef] [PubMed]

24. Kapogiannatou, A.; Paronis, E.; Paschidis, K.; Polissidis, A.; Kostomitsopoulos, N.G. Effect of light colour temperature and intensity on the behaviour of male C57CL/6J mice. Appl. Anim. Behav. Sci. 2016, 184, 135-140. [CrossRef] 
25. Rahman, S.A.; St Hilaire, M.A.; Lockley, S.W. The effects of spectral tuning of evening ambient light on melatonin suppression, alertness and sleep. Physiol. Behav. 2017, 177, 221-229. [CrossRef]

26. Yuda, E.; Yoshida, Y.; Ogasawara, H.; Hayano, J. Relaxation effects of organic light emitting diode lighting. Jpn. J. Physiol. Anthropol. 2018, 23, 23-28. (In Japanese)

27. Lucas, R.J.; Peirson, S.N.; Berson, D.M.; Brown, T.M.; Cooper, H.M.; Czeisler, C.A.; Figueiro, M.G.; Gamlin, P.D.; Lockley, S.W.; O'Hagan, J.B.; et al. Measuring and using light in the melanopsin age. Trends Neurosci. 2014, 37, 19. [CrossRef]

28. Measuring Melanopic Illuminance. Available online: http://lucasgroup.lab.manchester.ac.uk/research/ measuringmelanopicilluminance/ (accessed on 15 October 2019).

29. Kalsbeek, A.; Scheer, F.A.; Perreau-Lenz, S.; La Fleur, S.E.; Yi, C.X.; Fliers, E.; Buijs, R.M. Circadian disruption and SCN control of energy metabolism. FEBS Lett. 2011, 585, 1412-1426. [CrossRef]

30. Ni, J.; Shen, T.; Ebara, Y.; Koyamada, K.; Kawakami, Y.; Nakamura, Y. Reduction of the blue light hazard by adding a cyan light LED. J. Adv. Simul. Sci. Eng. 2018, 4, 44-63. [CrossRef]

31. Peng, M.-L.; Tsai, C.-Y.; Chien, C.-L.; Hsiao, J.C.-J.; Huang, S.-Y.; Lee, C.-J.; Lin, H.-Y.; Wen, Y.-C.; Tseng, K.-W. The influence of low-powered family LED lighting on eyes in mice experimental model. Life Sci. J. 2012, 9, 477-482.

32. Kraneburg, A.; Franke, S.; Methling, R.; Griefahn, B. Effect of color temperature on melatonin production for illumination of working environments. Appl. Ergon. 2017, 58, 446-453. [CrossRef]

33. Jacobs, G.H.; Neitz, J.; Deegan, J.F. Retinal receptors in rodents maximally sensitive to ultraviolet light. Nature 1991, 353, 655-656. [CrossRef]

34. Badoer, E. Hypothalamic paraventricular nucleus and cardiovascular regulation. Clin. Exp. Pharmacol. Physiol. 2001, 28, 95-99. [CrossRef]

35. Ebner, K.; Singewald, N. Individual differences in stress susceptibility and stress inhibitory mechanisms. Curr. Opin. Behav. Sci. 2017, 14, 54-64. [CrossRef]

36. Smith, S.M.; Vale, W.W. The role of the hypothalamic-pituitary-adrenal axis in neuroendocrine responses to stress. Dialogues Clin. Neurosci. 2006, 8, 383-395.

37. Alves-Simoes, M.; Coleman, G.; Canal, M.M. Effects of type of light on mouse circadian behaviour and stress levels. Lab. Anim. 2016, 50, 21-29. [CrossRef]

38. Chang, S.W.; Kim, H.I.; Kim, G.H.; Park, S.J.; Kim, I.B. Increased expression of osteopontin in retinal degeneration induced by blue light-emitting diode exposure in mice. Front. Mol. Neurosci. 2016, 9, 58. [CrossRef]

39. Jaadane, I.; Villalpando Rodriguez, G.E.; Boulenguez, P.; Chahory, S.; Carré, S.; Savoldelli, M.; Jonet, L.; Behar-Cohen, F.; Martinsons, C.; Torriglia, A. Effects of white light-emitting diode (LED) exposure on retinal pigment epithelium in vivo. J. Cell Mol. Med. 2017, 21, 3453-3466. [CrossRef]

40. Nakamura, M.; Kuse, Y.; Tsuruma, K.; Shimazawa, M.; Hara, H. The Involvement of the Oxidative Stress in Murine Blue LED Light-Induced Retinal Damage Model. Biol. Pharm. Bull. 2017, 40, 1219-1225. [CrossRef]

41. Vicente-Tejedor, J.; Marchena, M.; Ramírez, L.; García-Ayuso, D.; Gómez-Vicente, V.; Sánchez-Ramos, C.; de la Villa, P.; Germain, F. Removal of the blue component of light significantly decreases retinal damage after high intensity exposure. PLoS ONE 2018, 13, e0194218. [CrossRef]

(C) 2019 by the authors. Licensee MDPI, Basel, Switzerland. This article is an open access article distributed under the terms and conditions of the Creative Commons Attribution (CC BY) license (http://creativecommons.org/licenses/by/4.0/). 